\title{
The research of Medical Compression Stockings equipment based on 3D scanner
}

\author{
Gao Zhi ${ }^{\mathrm{a}}$, Liu Tingyu ${ }^{\mathrm{b}}$, and Shi Conghui ${ }^{\mathrm{c}}$ \\ School of Mechanical and Power Engineering, East China University of Science and Technology, \\ Shanghai 200237, China. \\ agaozhi@ecust.edu.cn, 'liutingyu1018@163.com,
}

Keywords: medical compression stockings; automatic measurement; 3D scanner; customized.

\begin{abstract}
The Compression stocking is one of the effective means to protect and cure varix, If people want to gain good effect from the medical compression stockings, they need to be provided with specific type of compression stockings which is designed based on the analysis of their leg shape. However, the domestic enterprises can only provide limited size of the medical compression stockings, the gradual pressure of the leg cannot satisfied the medical requirement, which means huge numbers of the patients cannot get the suitable compression stockings from the market and that can be bad for the treatment. Due to this situation, the project plans to develop a set of automatic recommendation system for compression stockings which can measure the shape of people' s legs automatically and then recommend the suitable type of the compression stockings to the patient.the proposed method can calculate the size of suitable compression stockings to satisfy the effect of pressure release.
\end{abstract}

\section{Introduction}

Medical compression stockings as a new hosiery product can promote venous blood return to the heart, the principle is as follows:The highest pressure is established in the ankle, and gradually decreased along the legs.the pressure on calf is $60-80 \%$ of the pressure on the ankle, the pressure on mid-thigh is $40-50 \%$ of the pressure on the ankle.the decline can promote venous blood stream of the lower extremity return to the heart which effectively relief the pressure of lower limb vein.

Liu studied the pressure distribution on the human body which found that the pressure on the legs is determined by the shape and structure of legs[1].Zhang Siwen proposed that the changes of leg circumference influence the pressure[2].however,there are only three sizes of medical compression stockings provided by domestic enterprises, while the size of each patient's ankle varies and the leg shape is different.If the sizes provided by enterprises cannot match the patient's leg size, there is no suitable pressure on different sections of the leg which will affect the efficacy of treatment.

In order to solve the problem, it is necessary to develop the medical compression stockings customized equipment.the equipment can accurately achieve automatic measurement of human leg size, and according to the measured leg size, the customization requirements can be proposed.

\section{Whole scheme design of customized equipment}

The development of compression stockings is mainly divided into three stages: (a) Force analysis of compression stockings, conclude the relationship among pressure, leg size and shape, yarn density and other parameters; (b) design the hardware system of leg size measurement based on 3D laser scanner, extract characteristic parameters of the leg and analyze shape of the leg,write the corresponding software of extracting size of the leg; (c) the customized stocking system is established by using $\mathrm{VC}++$ which realizes the archive of digital. 


\section{Force analysis of compression stockings}

The pressure exerted on the leg is not only related to the tension from stockings,but also depends on the radius of curvature of the leg. Theoretical analysis is based on Laplace formula[3].

$P=\frac{T}{r}$

Where $\mathrm{P}, \mathrm{T}, \mathrm{r}$ are the pressure, the tension of unit length, curvature radius of the leg, respectively. according to mechanics of material,stress-strain relationship under tensile condition is given by:

$\sigma=E \varepsilon$

Where $\sigma, \mathrm{E}, \varepsilon$ are the stress, Elastic Modulus, the strain, respectively.when drawing force is $\mathrm{T}$, therefore:

$\sigma=\frac{T}{S}$

Where $\mathrm{S}$ is the section area under the drawing force T.according to Eqs.(2)and(3), T can be written as:

$T=S E \varepsilon$

According to the definition of linear density,1dtex is equal to the weight of yarn $10^{6} \mathrm{~cm}$ long. suppose $S_{1}$ is the section area of the yarn when the density of yarn is 1 dtex. The section area $S$ when the density is $T_{t}$ can be calculated:

$S=T_{t} S_{1}$

According to Eqs.(4) and (5), T can be written by:

$T=T_{t} S_{1} E \varepsilon$

The physical meaning of $S_{1} E$ is that the force needed to produce 1 unit tensile strain when the density of the yarn is 1 dtex and the section area is $S_{1}$.the knitting technology of compression stockings shows that yarn density of each transverse arrangement is $T$ and there are $n$ transverse arrangements of the stocking per unit length.hence:

$T=n T_{t} S_{1} E \varepsilon$

Suppose $E_{m}=T_{t} S_{1} E, \mathrm{~T}$ is written as :

$T=n E_{m} \varepsilon$

The physical meaning of $E_{m}$ is that the force needed to produce 1 unit tensile strain when the density of the yarn is $T_{t}$ spandex wrap yarn is the main factor to provide force which decides the elastic recovery of the compression stockings.therefore, we only consider the line density of spandex in the theoretical analysis.the value of ${ }^{E_{m}}$ can get from the tensile test.the relationship between the pressure on the leg, the leg size and the knitted size is as follows:

$P=\frac{n E_{m} \varepsilon}{r}, \varepsilon=\frac{l-2 b}{2 b}, r=\frac{l}{2 \pi}$

Where $l, b$ are leg circumference, average width of stockings in the corresponding circumference position, respectively.

\section{Design of 3D laser scanner}

\section{Design of hardware system}

3D laser scanner is composed of electric machinery,laser unit,camera and computer.a laser and a camera form a scanning head. The principle of laser 3D scanner is that motor drives the lead screw,the platform moves up and down through the linear guide-way, data of the leg can be quickly obtained by the 3D scanner, finally,point cloud data of leg can be extracted by using self-developed software, therefore the device can quickly obtain the characteristic parameters of the leg by 
reconstructing the leg contour.

Arrangement of the scanning head is the difficulty of system design, it is necessary that four scanning heads get the maximum coverage of the leg and data proper overlapping.four laser lines should be in the same horizontal position and the intersection can compose a closed area like a circle.four scanning head get the same image at the same time. In order to avoid blind area,two scanning heads overlook the object,the others do the opposite.moreover, the angle of the same side of the scanning heads is $75^{\circ}$, the angle of the different side is $105^{\circ}$.

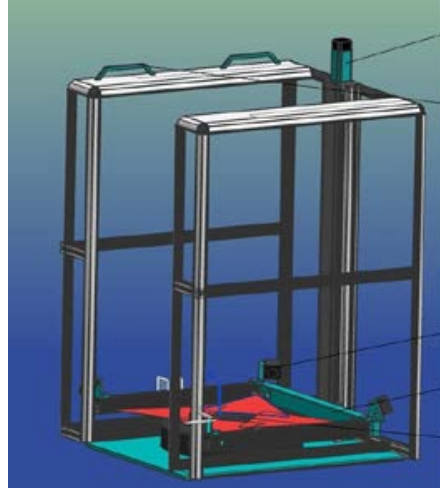

(a)

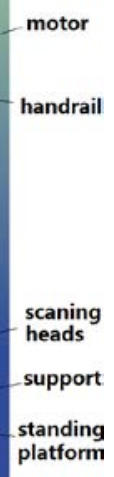
platform

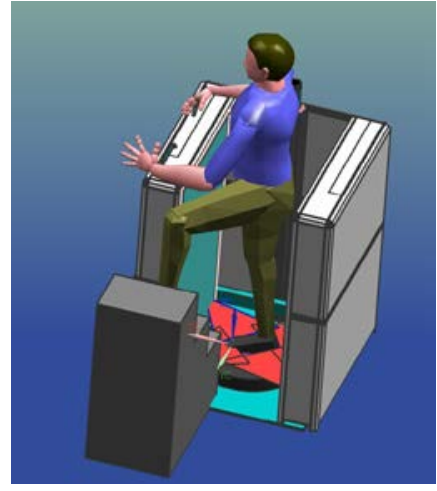

(b)

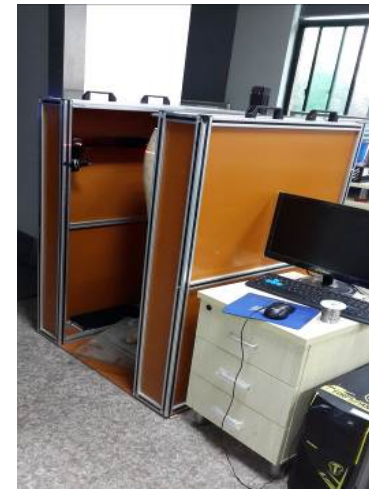

(c)

Fig. 1

Figures showing:(a)3D structure of leg scanning equipment;(b)effect drawing;and(c)3D laser leg scanner

\section{Design of software system}

Software system is established by VS2010,software interface in laser measuring system which includes scanning data, data processing, parameter extraction and generating report button is shown in Fig.2a.

The algorithm is divided into five parts:(a)central position extraction of laser strip;(b)calculating the space coordinates of the image point;(c)data fusion of four scanning heads;(d)data processing on point cloud data;(e)measurement of characteristic parts of the leg.

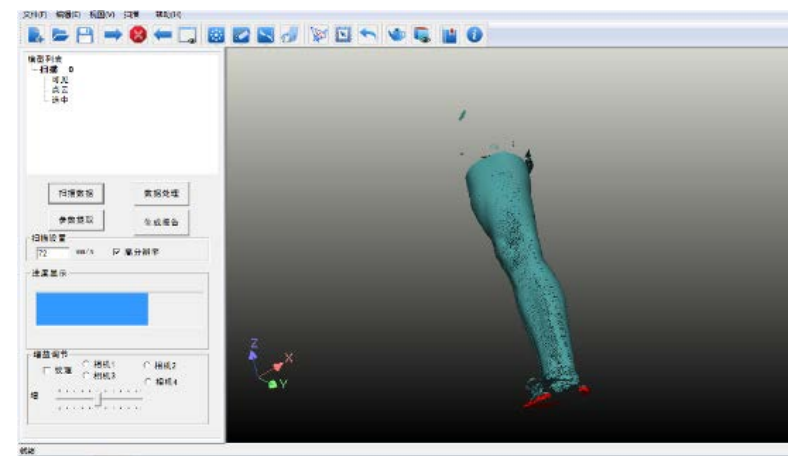

(a)

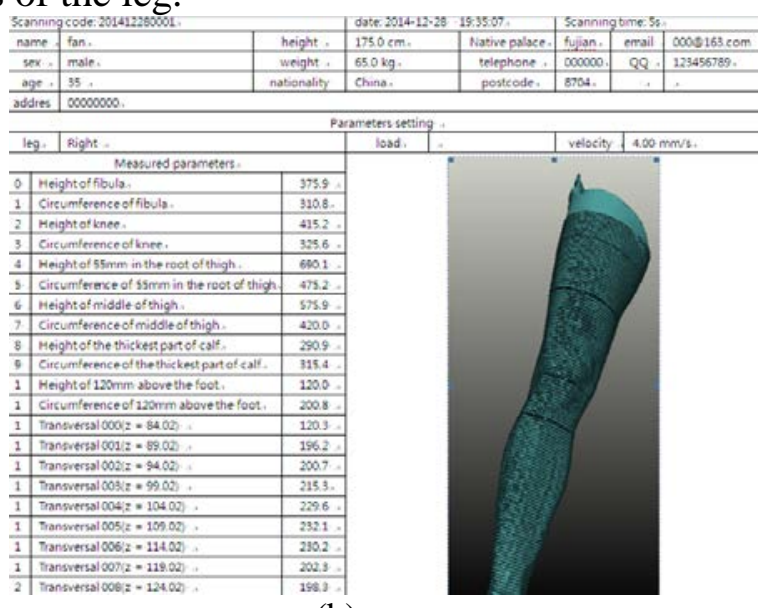

(b)

Fig. 2

Figures showing:(a)software interface of laser scanner;and(b)size report of the leg based on 3D laser scanning

Firstly, extracting the central position of laser strip based on varied-boundary Gaussian fitting[4]. secondly, eliminating distortion and transforming 2d image coordinates into 3d space coordinates[5]. obtaining the whole cloud points by registration of multiple rang cloud points based on ICP(Iterative Closest Point)[6].Surface triangulation is based on K-neighbor searching algorithm[7].Lastly,the dimensions of the desired sections are obtained by NURBS curve modeling[8].The size report of one experimenter is shown in Fig.2b. 


\section{Design of customization system}

The pressure decreases gradually from thigh to ankle,i.e.1.064,1.330,1.064,1.862,2.394kPa proposed by SIDEL[9].P, ${ }^{E_{m}}, 1$ in Eqs.(8)are known parameters, ${ }^{b}$ and the number of transverse arrangements $n$ are unknown parameters.enterprises can define one of $b$ and $n$ as the known parameter according to difficulty of production.

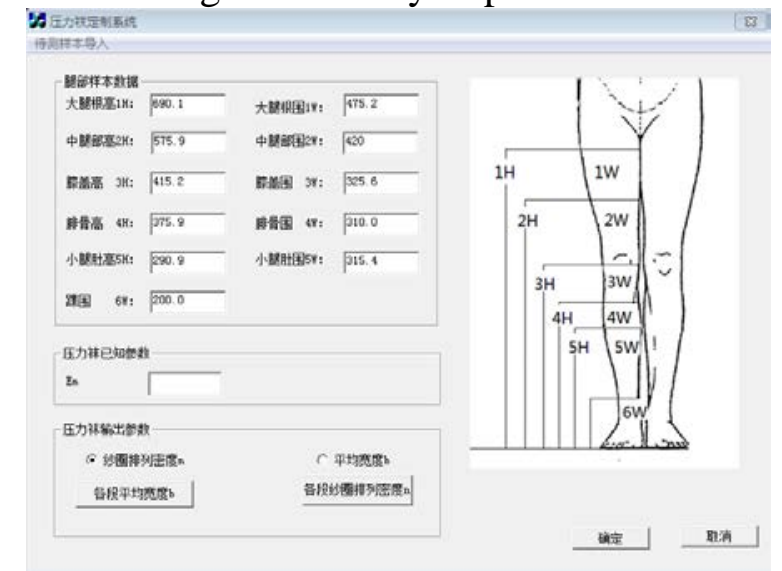

(a)

Fig. 3

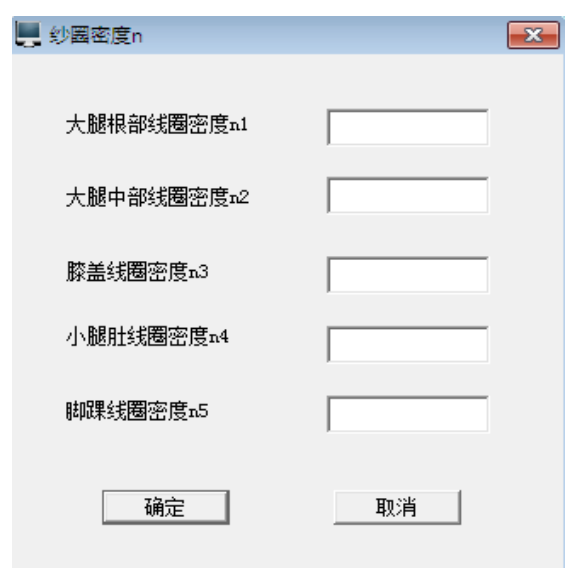

(b)

Figures showing:(a)the main-interface of customization system;and(b)the density of yarn $n$

Customization system of compression stockings is established by using $\mathrm{VC}++$,the main-interface is shown in Fig.3(a).import the leg data into the interface by clicking the sample button,if choosing $n$ as the known parameters,the density of yarn interface will show as Fig.3(b).when all the blank texts have been filled in, the program will calculate sizes of different parts of legs to realize the customization.the data will be saved in specified ACCESS,otherwise if $b$ is the known parameters, $n$ will be obtained by the customization program.

\section{Experimental Verification}

Using self-developed customization system to test the accuracy and stability of the algorithm.it can reach the following conclusions: (1) scan a cylindrical with a diameter of $110 \mathrm{~mm}$ for five times , the error of perimeter is within $\pm 1 \mathrm{~mm}$.(2) scan a randomly selected leg sample for five times through the equipment as is shown in table 1 . The errors of these five results are all within $\pm 0.5 \mathrm{~mm}$ which proves good stability of the algorithm.(3) errors may come from following reasons:(a)legs maybe tremble during the measurement;(b)As time goes on, muscle of legs will contract or swell. Import the characteristic parameters of legs form the scanner into customization system,customization requirements can be obtained quickly. Medical test of the patients who wear the customized compression stockings shows that new compression stockings fit legs well and can provide the suitable compression for the treatment.

\section{Summary}

Some problems,for instance,the size of stockings that patients need is inconsistent with the ones that it offered in hospital as well as the inefficiency in manual measurement can be solved through the development of customization device of the medical compression stockings.

The design of 3D scanning system is based on the principle of laser ranging. And the device can measure automatically without touching patients' legs. Moreover,it has a high accuracy of measurement and good repeatability.

$\mathrm{VC}++$ was used to develop the customization system in whole processing.it has not only 
accomplished the design of interface but the integration of every functional module. Test shows that the system can response rapidly to the customization of compression stockings due to the data that has been measured. And customization stockings have the advantages of offering segmentation pressure that patients need in therapy to ensure the efficacy.

Table 1 The stability and accuracy of the system (unit:mm)

\begin{tabular}{|c|c|c|c|c|c|c|c|c|}
\hline parameters time & 1 & 2 & 3 & 4 & 5 & $\begin{array}{l}\text { Avera } \\
\text { ge }\end{array}$ & $\begin{array}{l}\text { Manual } \\
\text { measurement }\end{array}$ & $\begin{array}{l}\text { erro } \\
\mathrm{r}\end{array}$ \\
\hline height of $55 \mathrm{~mm}$ in the root of thigh & $\begin{array}{l}658 . \\
7\end{array}$ & $\begin{array}{l}658 . \\
6\end{array}$ & 658.6 & $\begin{array}{l}658 . \\
6\end{array}$ & $\begin{array}{l}658 . \\
4\end{array}$ & $\begin{array}{l}658.5 \\
8\end{array}$ & 660 & $\begin{array}{l}1.4 \\
2\end{array}$ \\
\hline $\begin{array}{l}\text { circumference of } 55 \mathrm{~mm} \text { in the root of } \\
\text { thigh unde } 55 \mathrm{~mm}\end{array}$ & $\begin{array}{l}488 . \\
6\end{array}$ & $\begin{array}{l}488 . \\
7\end{array}$ & 488.7 & $\begin{array}{l}488 . \\
9\end{array}$ & $\begin{array}{l}489 . \\
0\end{array}$ & $\begin{array}{l}488.7 \\
8\end{array}$ & 490 & $\begin{array}{l}1.2 \\
2\end{array}$ \\
\hline height of middle of thigh & $\begin{array}{l}577 . \\
0\end{array}$ & $\begin{array}{l}577 . \\
0\end{array}$ & 576.9 & $\begin{array}{l}576 . \\
8\end{array}$ & $\begin{array}{l}576 . \\
6\end{array}$ & $\begin{array}{l}576.8 \\
6\end{array}$ & 578 & $\begin{array}{l}1.1 \\
4\end{array}$ \\
\hline circumference of middle of thigh & $\begin{array}{l}419 . \\
8\end{array}$ & $\begin{array}{l}419 . \\
9\end{array}$ & 420.0 & $\begin{array}{l}420 . \\
0\end{array}$ & $\begin{array}{l}420 . \\
2\end{array}$ & $\begin{array}{l}419.9 \\
8\end{array}$ & 418 & $\begin{array}{l}-1.9 \\
8\end{array}$ \\
\hline knee-high & $\begin{array}{l}445 . \\
4\end{array}$ & $\begin{array}{l}445 . \\
3\end{array}$ & 445.3 & $\begin{array}{l}445 . \\
3\end{array}$ & $\begin{array}{l}445 . \\
2\end{array}$ & 445.3 & 447 & 1.7 \\
\hline circumference of knee & $\begin{array}{l}337 . \\
4\end{array}$ & $\begin{array}{l}337 . \\
5\end{array}$ & 337.5 & $\begin{array}{l}337 . \\
5\end{array}$ & $\begin{array}{l}337 . \\
5\end{array}$ & $\begin{array}{l}337.4 \\
8\end{array}$ & 339 & $\begin{array}{l}1.5 \\
2\end{array}$ \\
\hline height of fibula & $\begin{array}{l}381 . \\
2\end{array}$ & $\begin{array}{l}381 . \\
2\end{array}$ & 381.1 & $\begin{array}{l}381 . \\
0\end{array}$ & $\begin{array}{l}381 . \\
0\end{array}$ & 381.1 & 380 & -1.1 \\
\hline circumference of fibula & $\begin{array}{l}310 . \\
6\end{array}$ & $\begin{array}{l}310 . \\
8\end{array}$ & 310.8 & $\begin{array}{l}310 . \\
8\end{array}$ & $\begin{array}{l}310 . \\
9\end{array}$ & $\begin{array}{l}310.7 \\
8\end{array}$ & 310 & $\begin{array}{l}-0.7 \\
8\end{array}$ \\
\hline height of calf & $\begin{array}{l}309 . \\
8\end{array}$ & $\begin{array}{l}309 . \\
8\end{array}$ & 309.6 & $\begin{array}{l}309 . \\
5\end{array}$ & $\begin{array}{l}309 . \\
5\end{array}$ & $\begin{array}{l}309.6 \\
4\end{array}$ & 310 & $\begin{array}{l}0.3 \\
6\end{array}$ \\
\hline circumference of calf & $\begin{array}{l}318 . \\
5\end{array}$ & $\begin{array}{l}318 . \\
6\end{array}$ & 318.7 & $\begin{array}{l}318 . \\
9\end{array}$ & $\begin{array}{l}319 . \\
0\end{array}$ & $\begin{array}{l}318.7 \\
4\end{array}$ & 317 & $\begin{array}{l}-1.7 \\
4\end{array}$ \\
\hline circumference of ankle & $\begin{array}{l}203 . \\
3\end{array}$ & $\begin{array}{l}203 . \\
3\end{array}$ & 203.3 & $\begin{array}{l}203 . \\
3\end{array}$ & $\begin{array}{l}203 . \\
2\end{array}$ & $\begin{array}{l}203.2 \\
8\end{array}$ & 205 & $\begin{array}{l}1.7 \\
2\end{array}$ \\
\hline
\end{tabular}

\section{References}

[1] LIU R, MSC, KWOK Y L, et a1. Objective evaluation of skin pressure distribution of graduated elastic compression stockings[J]. Dermatologic Surgery, 2005, 31(6): 615-624.

[2] Zhang Siwen, Wang wenzu. Performance testing and trial knitting of anti-embolism stockings[J]. journal of Donghua university (natural science), 2011,37(1):46-50.

[3] Wang Zhi, Li Hong. The theoretical analysis and calculation of compression stockings[J]. Guizhou water power, 2012, 40(12):38-43.

[4] Gao Shiyi, Yang Kaizhen. Research on central position extraction of laser strip based on varied-boundary Gaussian fitting[J]. Chinese Journal of Scientific Instrument, 2011, 32(5): 1132-1137.

[5] Zhang Z. A flexible new technique for camera calibration[J]. IEEE Transactions on Pattern Analysis and Machine Intelligence, 2000, 22(11): 1330-1334.

[6] Besl P J, Mckay N D. A method for registration of 3-D shapes[J]. IEEE Transactions on Pattern Analysis and Machine Intelligence, 1992,14(2): 239-256.

[7] LEE Hyung-woo, KIM Ki-chan, LEE Ju. Review of maglev train technologies[J]. IEEE Transaction on Magnetics, 2006,42(7): 1917-1925.

[8] Les Piegl, Wayne Tiller. The NURBS Book[M]. Berlin : SpringerVerlag,1995.

[9] SIGLE B;EDELSTEIN A L;SAVITCH L Type of Compression for Reducing Venous Stasis:A Study of Lower Extremities During Inactive Recumbency[J]. Archives of Surgery, 1975(2). 